\title{
ARCO DE CHARLES MAGUEREZ: REFLETINDO ESTRATÉGIAS DE METODOLOGIA ATIVA NA FORMAÇÃO DE PROFISSIONAIS DE SAÚDE
}

\author{
Charles maguerez arc: reflecting methodology strategies on active training for health \\ professionals.
El arco de charles maguerez: una reflexión sobre las estrategias de metodología activa para la formación de los profesionales del área de la salud

Marta Lenise do Prado ${ }^{1}$

Sandra Hilda Sobrinho ${ }^{4}$
Manuela Beatriz Velho²

Daniela Simoni Espíndola ${ }^{3}$

\section{RESUMO}

A educação superior na área da saúde vem passando por profundas mudanças para acompanhar as correntes de pensamento que norteiam a formação do profissional e do docente. Novas tendências pedagógicas apontam a necessidade da formação de um profissional crítico-reflexivo, capaz de transformar sua realidade social. Este artigo trata-se de um relato de experiência que teve por objetivo apresentar as vivências no desenvolvimento de um seminário durante uma disciplina do mestrado, no curso de PósGraduação em Enfermagem, ao abordar o tema Metodologia Ativa como a Problematização e a Aprendizagem Baseada em Problemas, por meio da utilização do Arco de Charles Maguerez, seguindo as etapas de observação da realidade, pontos-chave, teorização, hipótese de solução e aplicação na realidade. Essa experiência vivida, a partir da proposta pedagógica, foi significativa e possibilitou aos alunos/docentes repensar e reconstruir suas próprias práticas pedagógicas.

Palavras-chave: Aprendizagem baseada em problemas. Educação superior. Enfermagem. Métodos.

\begin{abstract}
The academic education in the health sector is undergoing profound changes to follow the school of thought that guide the training for professionals and instructor. New pedagogical tendencies indicate the need for educational training of a criticalreflective professional, able to transform their social reality. This article shows an experience report that aimed to present the experiences in the development of a seminary during a Master class, in the course of pos-graduation in nursing, when approaching the active methodology theme as the Issues and Learning based in problems, through the use of Charles Maguerez Arc, following the steps of observing the reality, key-points, theorizing, hypothesis and application for real. This experience, from the pedagogical proposal, was significant and enabled the students / teachers to rethink and rebuild their own teaching practices.
\end{abstract}

Keywords: Problem-Based Learning. Education, Higher. Nursing. Methods.

\section{Resumen}

La educación superior en el área de la salud está experimentado cambios profundos para seguir las corrientes de pensamiento que orientan la formación del profesional y del docente. Las nuevas tendencias pedagógicas indican la necesidad de formación de un profesional crítico y reflexivo, capaz de transformar su realidad social. Este artículo es un relato de experiencia que tiene por objetivo presentar las vivencias en el desarrollo de un seminario para el curso de maestría de Postgrado en Enfermería, al abordar el tema: Metodología activa como Problematización y Aprendizaje Basado en Problemas, mediante el uso del Arco de Charles Maguerez, según las etapas de observación de la realidad, puntos importantes, la teoría, hipótesis de soluciones e implementación en la realidad. La experiencia vivida, según esa propuesta pedagógica, fue importante y permitió a los estudiantes y a los maestros repensar y reconstruir sus propias prácticas pedagógicas.

Palabras clave: Aprendizaje Basado en Problemas. Educación Superior. Enfermería. Métodos.

\footnotetext{
'Doutora em Enfermagem, Professora Associada do Departamento de Enfermagem e do Programa de Pós-Graduação em Enfermagem da Universidade Federal de Santa Catarina. Membro do Grupo de Pesquisa em Educação em Enfermagem e Saúde (EDEN). Florianópolis-SC. Brasil. E-mail: mpradop@ccs.ufscbr;;'Enfermeira Especialista em Obstetrícia, Mestranda em Enfermagem do Programa de Pós-Graduação em Enfermagem (PEN) da Universidade Federal de Santa Catarina (UFSC), bolsista CNPq. Membro do Grupo de Pesquisa em Enfermagem na Saúde da Mulher e do Recém-nascido (GRUPESMUR). Florianópolis- SC. Brasil. E-mail: manuelavelho@hotmail.com; ${ }^{\text {Fisioterapeuta }}$ Especialista em Saúde da Mulher e Aspectos Interdisciplinares, Mestranda em Enfermagem do Programa de Pós-Graduação em Enfermagem (PEN) da Universidade Federal de Santa Catarina (UFSC), bolsista CAPES/REUNI. Membro do Grupo de Estudos de História da Enfermagem e Saúde (GEHCES). Florianópolis-SC. Brasil. E-mail: daniela.d@@hotmail.com; “Enfermeira, Mestranda em Enfermagem do Programa de Pós-Graduação em Enfermagem (PEN) da Universidade Federal de Santa Catarina (UFSC). Membro do Grupo de Pesquisa Cuidando e Confortando (C\&C). Florianópolis-SC. Brasil. E-mail: sandrahilda@hotmail.com; ${ }^{5}$ Doutora em Enfermagem, Professora Associada do Departamento de Enfermagem e do Programa de Pós-Graduação em Enfermagem da Universidade Federal de Santa Catarina. Membro e Líder do Grupo de Pesquisa em Educação em Enfermagem e Saúde (EDEN). Florianópolis - SC. Brasil. E-mail: oivania@ccs.ufsc.br
} 


\section{INTRODUÇÃO}

A educação superior na área da saúde, ao longo de sua trajetória histórico-pedagógica, vem passando por profundas mudanças para acompanhar, em termos de correntes de pensamento, as concepções que norteiam a formação do profissional e do docente. Neste contexto, o modelo de ensino tradicional vem sendo gradativamente substituído por novas tendências pedagógicas, as quais apontam para a necessidade da formação de um profissional crítico-reflexivo, capaz de transformar a realidade social do seu cotidiano, minimizando injustiças e desigualdades. A formação deste profissional deve conduzir para o compromisso com a clientela o que proporcionará a melhora da qualidade de saúde da população, atendendo aos princípios do Sistema Único de Saúde (SUS). ${ }^{1}$

Em nosso entendimento, para que os profissionais da área da saúde possam atuar na docência na sociedade atual, é essencial compreender as tendências pedagógicas e filosóficas que permeiam o ensino na saúde, utilizando recursos metodológicos inerentes às novas concepções em educação.

As concepções de práticas educativas são norteadas pelas tendências pedagógicas, ou seja, o modo pelo qual é compreendido o processo de ensino-aprendizagem. Estas tendências referem-se à forma predominante pela qual se efetua o processo educativo, e podem ser classificadas em pedagogia tradicional, renovada, por condicionamento e crítica. $^{2}$

$\mathrm{Na}$ pedagogia tradicional, as ações de ensino apresentam-se centradas na transmissão de conhecimentos pelo professor ao aluno, sendo o professor, o único responsável pela condução do processo educativo, uma autoridade máxima no que concerne as estratégias de ensino. Já como uma nova tendência pedagógica, surge a pedagogia crítica, na qual o professor assume o papel de mediador, ao conduzir os alunos à observação da realidade e apreensão do conteúdo que extraem dela, um processo educativo que visa a transformação social, econômica e política, além da superação das desigualdades sociais. ${ }^{2}$

No contexto das novas tendências pedagógicas, a Metodologia Ativa é uma das possíveis estratégias, para qual o aluno é o protagonista central, ou seja, corresponsável pela sua trajetória educacional e o professor apresenta-se como coadjuvante, um facilitador das experiências relacionadas ao processo de aprendizagem ${ }^{3}$.

A utilização de Metodologia Ativa é um desafio para os educadores, para que exerçam uma práxis criadora, na qual seja possível a formação de sujeitos críticoreflexivos, corresponsáveis pela construção de seu próprio processo de aprendizado ao longo da vida. ${ }^{3}$ Sua utilização implica não somente conhecer os modos de operacionalização, mas fundamentalmente os princípios pedagógicos que a sustentam, ou seja, os princípios da pedagogia crítica.
Prado ML ,Velho MB ,Espíndola DS , Sobrinho SH,Backes VMS

A pedagogia crítica tem como um dos seus mais fortes representantes o educador Paulo Freire, e seus fundamentos tem subsidiado inúmeras experiências pedagógicas na área da saúde, tanto na educação profissional como na educação em saúde. Para Freire, o aluno precisa ser o protagonista de seu processo de aprendizagem e ao professor cabe a tarefa de despertar a curiosidade epistemológica.

No processo de aproximação à temática Metodologia Ativa, realizamos leituras exaustivas consultando livros, artigos científicos em bases de dados nacionais e internacionais e diálogos com especialistas no assunto, e obtivemos muitas informações. Assim, foi possível compreender dois modos fundamentais para sua operacionalização: a Problematização e Aprendizagem Baseada em Problemas.

A metodologia da Problematização é utilizada em situações nas quais os temas estejam relacionados com a vida em sociedade, tendo como referência o Método do Arco de Charles Maguerez, apresentado pela primeira vez por Bordenave e Pereira, em 1982. ${ }^{3}$ Trata-se de um caminho metodológico capaz de orientar a prática pedagógica de um educador preocupado com o desenvolvimento de seus alunos e com sua autonomia intelectual, visando o pensamento crítico e criativo, além da preparação para uma atuação política. ${ }^{4}$ Também nos instrumentalizamos para o nosso encontro, utilizando a proposta metodológica da Aprendizagem Baseada em Problemas, na qual se preparam situações, ou seja, temas de estudo que o aluno deverá saber e dominar, sendo determinados previamente quais conhecimentos o aluno deverá possuir para cada uma delas. Cada tema é transformado em um problema para ser discutido em grupo. ${ }^{4}$

No Brasil, em uma retrospectiva da aplicação da Metodologia Ativa, identificamos que o seu uso na educação formal é algo recente, a partir dos anos 2000, com a implementação das Diretrizes Curriculares Nacionais, para os Cursos de Graduação em Saúde, com o intuito de buscar uma formação dos profissionais de saúde orientada para o SistemaÚnico de Saúde(SUS). Nesse processo, várias ações foram desencadeadas: o Programa Aprender SUS, a Política Nacional de Educação Permanente como estratégia do SUS no desenvolvimento de trabalhadores para o setor e o Programa Nacional de Reorientação da Formação Profissional em Saúde-Pró-Saúde. ${ }^{5}$

Assim, este artigo tem por objetivo relatar as vivências no desenvolvimento do tema Metodologia Ativa por meio da utilização do Arco de Charles Maguerez em um seminário, durante uma disciplina do Curso de Mestrado em Enfermagem, de uma instituição federal de ensino.

\section{APRENDENDO A ENSINAR E APRENDER}

A disciplina de Concepções Teórico-Metodológicas da Educação em Saúde e Enfermagem do curso de Mestrado em Enfermagem, da Universidade Federal de Santa Catarina (UFSC), foi desenvolvida no segundo semestre de 2009. 0 Plano de 
Ensino da disciplina contempla os seguintes temas: Perspectivas teóricas, políticas e legais da formação profissional e educação em saúde e Enfermagem - Bases didáticopedagógicas da prática educativa.

Por meio de discussão com o grupo, a disciplina possibilita uma visão ampla sobre temas atuais como: ensino inovador versus ensino tradicional, a preparação pedagógica dos profissionais, currículos centrados na doença, com enfoque no modelo hospitalocêntrico, entre outros. Neste cenário, tivemos o desafio de abordar o tema: Metodologia Ativa no processo de ensinar-aprender com nossos colegas, alunos do mestrado.

Nosso desafio foi o de apreender acerca do tema Metodologia Ativa e aplicá-la no contexto da disciplina, utilizando formas para sua operacionalização, até porque precisávamos ter coerência entre o discurso e a prática, já que não é possível ensinar Metodologia Ativa, utilizando metodologias tradicionais, certo?

Portanto, nossa escolha foi de nos colocarmos como facilitadoras da disciplina (e não como professoras no modo tradicional de ensinar) e posicionar nossos colegas, alunos do mestrado, como protagonistas neste processo; e ficamos responsáveis por conduzir a turma para a compreensão e vivência da Metodologia Ativa. Escolhemos então experenciar a aplicação de um modelo problematizador de ensino.

A fundamentação teórica da metodologia da Problematização tem origem na concepção da educação histórico-crítica, com propósito maior de preparar o estudante/ ser humano na tomada de consciência do seu mundo e atuar intencionalmente para transformá-lo. ${ }^{6}$

Para isso, utilizamos o Arco de Charles Maguerez, o qual é uma das estratégias de ensino-aprendizagem para o desenvolvimento da Problematização. Consta de cinco etapas que acontecem a partir da realidade social: a observação da realidade, os pontos-chaves, a teorização, as hipóteses de solução e aplicação à realidade, que estão descritas a seguir.?

\section{PRIMEIRA ETAPA: OBSERVANDO A REALIDADE}

Para dar início a primeira etapa do Arco de Charles Maguerez, solicitamos aos alunos a divisão em quatro grupos (5 alunos por grupo) e propusemos a cada grupo a atividade de planejar uma aula utilizando Metodologia Ativa. 0 tema da aula foi de livre escolha, e os alunos foram motivados a utilizar suas vivências, experiências e afinidades na construção da proposta. Era preciso definir qual o tema a ser abordado, como seria desenvolvido o assunto, com quais recursos, e como seria a avaliação do conteúdo desenvolvido. Após a discussão em pequenos grupos, seguiu-se a apresentação de cada proposta, conforme compreensão prévia do tema pelos alunos.

Esta primeira etapa, observação da realidade, consiste na participação ativa dos sujeitos (neste caso, dos alunos) para um olhar atento da realidade, efetuando assim uma primeira leitura na qual o tema a ser trabalhado está inserido ou acontecendo na vida real. É o momento em que os sujeitos envolvidos podem olhar atentamente para a realidade, escolhendo aspectos que precisem ser desenvolvidos, trabalhados, revisados ou melhorados. ${ }^{6-7}$ Para essa etapa, 0 professor pode utilizar diferentes estratégias (visitas, filmes, dramatização, reportagens/notícias, discussão em grupo, entrevistas com população e especialistas, dentre outras) as quais permitam aos alunos uma aproximação da realidade.

No nosso caso, a realidade a ser observada era a de ser docente de enfermagem ou de outras áreas da saúde (fisioterapia, fonoaudiologia e serviço social), já que muitos alunos do curso de mestrado são também professores ou já haviam exercido tal função, ainda que temporariamente. Então, nossa estratégia foi a de promover uma "rememoração" do seu processo de ensinar, fazendo-os revisitar suas experiências no planejamento das atividades docentes.

\section{SEGUNDA ETAPA: IDENTIFICANDO OS PONTOS-CHAVE}

Nessa segunda etapa, os sujeitos realizam uma eleição do que foi observado na realidade. Analisa-se o que é realmente importante, identificam-se os pontos-chaves do problema ou assunto em questão e as variáveis determinantes da situação. É o momento de síntese após a etapa da escolha do que será estudado sobre o problema, os aspectos que precisam ser conhecidos e melhor compreendidos, para buscar uma resposta ao problema, que para nós era a aplicação de Metodologia Ativa no processo ensino-aprendizagem. ${ }^{6-7}$

Nessa experiência, para a definição dos pontos-chaves, as facilitadoras suscitaram questionamentos que conduziram a discussões, contribuindo para reflexões sobre o tema em questão.

Para tornar este relato de experiência mais atrativo, as aulas planejadas pelos alunos não serão descritas em sua íntegra, apenas alguns tópicos por meio da apresentação das discussões realizadas com o grupo. No planejamento realizado pelos alunos, as estratégias propostas para observação da realidade foram: apresentação de filmes, exposição de figuras, elaboração de desenhos, perguntas norteadoras que emergiram da experiência dos alunos, incentivo a leitura e construção de dramatizações.

Após o relato dos alunos, surgiram questionamentos decorrentes do processo de reflexão do grupo, a saber: As aulas que foram propostas utilizavam Metodologia Ativa? Houve a participação ativa dos alunos na construção do conhecimento?; Pode ser aplicada Metodologia Ativa em grandes grupos ou somente em grupos pequenos?; Como os temas surgiram para serem trabalhados em cada grupo nas aulas propostas? A escolha do tema a ser trabalhado surgiu de uma situação problema predeterminada pelo professor ou emergiu da observação da realidade pelos alunos?; É preciso material apropriado, estrutura física, para implementar o ensino com Metodologia Ativa? 
Nesta discussão, esta e outras perguntas se tornaram pontos-chave a serem trabalhados na próxima etapa e foram sintetizadas assim: quais os modos de aplicação de Metodologia Ativa? Como operacionalizar uma Metodologia Ativa?

\section{TERCEIRA ETAPA: TEORIZANDO}

Na terceira etapa, teorização, os alunos do mestrado foram dispostos em círculo e fomentamos a discussão sobre a origem do tema: Metodologia Ativa e as diferentes formas de operacionalização, sua inserção no ensino superior e a sua relação com as políticas públicas. Posteriormente, instrumentalizamos os alunos com a leitura de um texto que abordava o tema Problematização e Aprendizagem Baseada em Problemas, ${ }^{4}$ o qual aponta o caminho metodológico de cada processo, os pontos semelhantes e divergentes de cada proposta.

A teorização, terceira etapa do Arco de Charles Maguerez, é o momento em que os sujeitos passam a perceber o problema e indagar o porquê dos acontecimentos observados nas fases anteriores. Uma teorização bem desenvolvida leva o sujeito a compreender o problema, não somente em suas manifestações baseadas nas experiências ou situações, mas também os princípios teóricos que os explicam. Nesse momento de teorização acontecem as operações mentais analíticas que favorecem o crescimento intelectual dos alunos. Todos os envolvidos no processo devem estudar o assunto. ${ }^{6-7}$

Para compreensão do leitor, apresentamos neste momento as propostas metodológicas da Aprendizagem Baseada em Problemas e Problematização, trabalhadas com o grupo na etapa de teorização.

A proposta da Aprendizagem Baseada em Problemas no processo de ensinar deve oportunizar aos alunos o uso da intuição para investigação e criação; esta formação os conduz a desenvolver o raciocínio, a pesquisa e a resolução de problemas, necessários para um mundo que vive profundas mudanças. ${ }^{8} \mathrm{~A}$ utilização deste método teve início com a formação de profissionais médicos, o qual possibilitava aos alunos a investigação de situações, desenvolvendo o raciocínio clínico e a compreensão das ferramentas que tinham a sua disposição. Permitia aos alunos um aprofundamento e progressão dos conhecimentos, de forma a permanecer atualizados em suas áreas. ${ }^{8}$

Para se trabalhar com a Aprendizagem Baseada em Problemas, o professor inicia suas atividades bem antes do contato com os alunos. Ele precisa optar pela sua aplicação ao longo de todo um curso, uma disciplina, ou utilizar-se dela em momentos específicos. Com esta definição, o professor pode desenvolver os problemas de duas maneiras: através do professor ou de um grupo de professores, previamente ao início das atividades, que direcionam determinados conteúdos e capacidades específicas; ou podem emergir do interesse dos alunos, durante a discussão de problemas, em que o professor
Prado ML ,Velho MB ,Espíndola DS , Sobrinho SH,Backes VMS

aproveita a oportunidade para trabalhar os conteúdos. Neste percurso, o professor adquire uma postura de facilitador e guia os alunos na trajetória pela busca das respostas, avaliando o processo. $^{8}$

0 desenvolvimento desta metodologia inicia em um determinado grupo com o incentivo à discussão de um problema. Ao dar continuidade a este processo, são feitos estudos individuais, principalmente em bibliotecas, que visam à obtenção de conhecimentos predeterminados, podendo ser feita consulta a professores especialistas. Com o retorno do grupo, são realizadas novas discussões sobre o problema, consolidando os conhecimentos adquiridos. ${ }^{4}$

Em contrapartida, a metodologia da Problematização é uma proposta de ensino, estudo e trabalho que, conforme citado anteriormente, aborda situações cujos temas relacionamse à vida em sociedade, caracterizando-se como ponto de partida e chegada dos estudos, pelos sujeitos envolvidos. A escolha por esta metodologia requer modificações na postura do professor e dos alunos, para reflexão e crítica aos temas; objetiva a mobilização dos alunos para agir politicamente enquanto cidadãos e profissionais em formação, um repensar e reconstruir a prática, aproximando o mundo da educação e 0 mundo do trabalho. ${ }^{3-4}$

\section{QUARTA ETAPA: IDENTIFICANDO HIPÓTESES DE SOLUÇÃO}

Na aplicação da quarta etapa do Arco de Charles Maguerez com os alunos, hipótese de soluções, propusemos com os alunos, a reestruturação da aula elaborada por eles na primeira etapa, utilizando Metodologia Ativa, deixando-os livres para a escolha do método. A quarta etapa do Arco de Charles Maguerez consiste na elaboração de alternativas viáveis para solucionar os problemas identificados, de maneira crítica e criativa, a partir do confronto entre teoria e realidade. ${ }^{3}$

A instrumentalização dos alunos através da etapa da teorização permitiu a reestruturação das aulas elaboradas na etapa hipóteses de soluções, momento em que nossos colegas refletiram sobre estas e sobre as estratégias de ensinoaprendizagem, o qual permitiu um olhar mais analítico.

Observamos, durante a apresentação das aulas reestruturadas, que permaneceram algumas incertezas sobre a aplicação do método da Problematização e da Aprendizagem Baseada em Problemas. Entretanto, as discussões com as facilitadoras e professoras da disciplina esclareceram os pontos conflitantes, e este momento possibilitou a consolidação dos conhecimentos adquiridos.

\section{QUINTA ETAPA: APLICAÇÃO À REALIDADE}

Na quinta etapa do Arco de Charles Maguerez, aplicação à realidade, os sujeitos envolvidos são levados à construção de novos conhecimentos para transformar a 
realidade observada, por meio das hipóteses anteriormente planejadas. ${ }^{3}$

Nesta etapa, os alunos refletiram sobre os conhecimentos prévios existentes quanto à Metodologia Ativa e a apreensão dos conhecimentos sobre a fundamentação teórica da Aprendizagem Baseada em Problemas e a Problematização, através de questionamentos como: 0 que eu preciso para solucionar o problema? Como podemos transformar a realidade? Quais os desafios para utilização da Metodologia Ativa?

Ao finalizar nosso encontro, percebemos a surpresa dos alunos ao apresentarmos o planejamento e a execução do Arco de Charles Maguerez com eles implementado (Figura 1), o que os levou a exercitarem a ação-reflexão-ação e a contribuição das facilitadoras para a transformação da realidade dos alunos.

\section{REFLETINDO SOBRE O ENSINAR}

A vivência desta prática pedagógica permitiu desenvolver um processo de ação-reflexão-ação das atividades docentes e assistenciais exercidas por nós, a partir da aplicação do Arco de Charles Maguerez, uma construção de nossa trajetória no processo de aprender a ensinar. Para os alunos, observamos a transformação da realidade durante o desenvolvimento do tema, ao ampliar suas compreensões sobre a Metodologia Ativa.

Durante a aplicação do Arco de Charles Maguerez, percebemos que esta experiência estimulou a curiosidade e a manutenção do interesse, dos alunos do mestrado, no alcance dos objetivos do processo de ensino-aprendizagem. A atividade conduziu os alunos ao aprender a aprender, um repensar e reconstruir a educação fundada na prática cotidiana do trabalho, com futuras repercussões na qualificação e valorização profissional.

Esta prática inovadora no processo ensinoaprendizagem apresenta-se em construção, ela contribui para a formação de um profissional crítico-reflexivo, e serão estes os profissionais que poderão dar continuidade a estas ações. Para isso, faz-se necessária a capacitação dos docentes, no exercício da prática reflexiva, para que sejam capazes de estimular no aluno o exercício da pergunta, possibilitando a imersão consciente do homem no mundo de sua experiência, um mundo carregado de conotações, valores, intercâmbios simbólicos, correspondências afetivas, interesses sociais e cenários políticos. ${ }^{9}$ Neste cenário, o professor precisa assumir uma posição de facilitador do processo de aprendizagem do aluno, proporcionando experiências adequadas e significativas para despertar no aluno uma atitude investigativa de curiosidade perante o mundo. ${ }^{10}$

A prática pedagógica precisa levar em conta as potencialidades dos alunos, contribuindo para a formação de profissionais mais bem qualificados e mais humanos; opor tunizando o resgate de suas necessidades e valorizando seu contexto e individualidade, minimizando as falhas e desigualdades das políticas de saúde e educação de nosso país. Todo este contexto auxilia para a melhoria da qualidade da assistência de enfermagem e 0 aprimoramento do ensino superior. ${ }^{11}$ Por isso, essa experiência vivida, a partir da proposta pedagógica de uma disciplina em um Curso de Mestrado em Enfermagem, foi significativa e possibilitou ao alunos/docentes repensar e reconstruir suas próprias práticas pedagógicas.

Figura1: Planejamento do Arco da Problematização de Charles Maguerez.

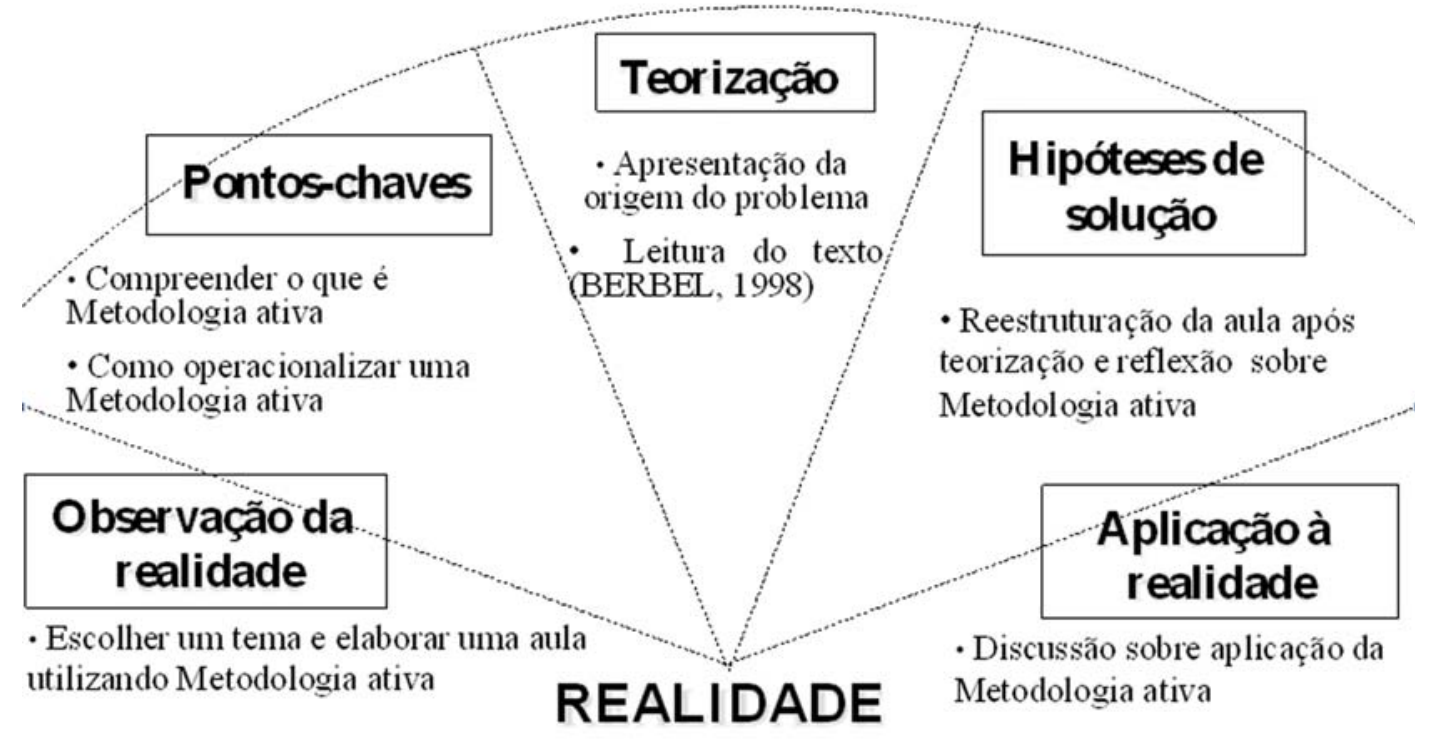

PROBLEM A: Aplicação da Metodologia ativa no processo ensino-aprendizagem. 


\section{REFERÊNCIAS}

1 Rodrigues J, Zagonel, IPS, Mantovani, MF. Alternativas para a prática docente no ensino superior de enfermagem. Esc Anna Nery. [periódico on-line]. 2007 jun; [citado 2010 abr 05]; 11 (02): [aprox.5 telas]. Disponível em: http://www.revenf.bvs.br/scielo

2 PereiraALF. As tendências pedagógicas e a prática educativa nas ciências da saúde. Cad Saude Publica. [periódico on-line]. 2003 set/out; [citado 2011 maio 17]; 19 (05): [aprox.8 telas]. Disponível em:http:// www.scielo.br/scielo

3 Reibnitz KS, Prado ML. Inovação e educação em enfermagem. Florianópolis: Cidade Futura; 2006.

4 Berbel NAN. A problematização e a aprendizagem baseada em problemas: diferentes termos ou diferentes caminhos? Interface: comunic, saude, educ. [periódico on-line]. 1998 fev; [citado 2009 dez 03]; 2(2): [aprox.16 telas]. Disponível em: http://www.scielo.br/scielo.

5 Rodrigues RA, Caldeira S. Movimentos na educação superior, no ensino em saúde e na enfermagem. Rev Bras Enferm. [periódico na internet]. 2008 set/out; [citado 2009 dez 03]; 61 (5): [aprox.8 telas]. Disponível em:http://www.scielo.br/scielo

6 Berbel NAN. Metodologia da problematização: fundamentos e aplicações. Londrina: Ed INP/UEL; 1999.

7 Bordenave JD, Pereira AMP. Estratégias de ensino-aprendizagem. 25a ed. Rio de Janeiro: Vozes; 2004.

8 Delisle R. Como realizar a aprendizagem baseada em problemas. Lisboa: ASA Editores II; 2000.

9 Gomez AIP. A função e formação do professor no ensino para a compreensão de diferentes perspectivas. In: Sacristàn JC, Gómez AIP. Compreender e transformar o ensino. Porto Alegre: Artes Médicas; 1998. p.353-80.

10 Medina-Moya JL, Prado ML. El curriculum de enfermería como prototipo de tejné: racionalidad instrumental y tecnológica. Texto\& Contexto Enferm. [periódico on-line]. 2009 dez; [citado 2010 jan 20]; 18(4): [aprox.10 telas]. Disponível em: http://www.scielo.br/scielo

11 Mostardeiro SCTS. Refletindo sobre a formação do enfermeiro: a prática docente a partir do imaginário pedagógico. Esc Anna Nery. [periódico on-line]. 2004 abr; [citado 2010 abr 05]; 8 (1): [aprox.5 telas]. Disponível em:http://www.eean.ufrj.br 